\title{
Being a hematologist
}

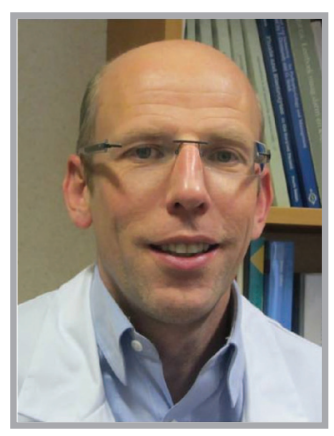

Michel Delforge* speaks to Roshaine Gunawardana, Managing Commissioning Editor: Michel Delforge is a senior clinical investigator and Professor of Medicine at the Department of Hematology of the Catholic University, Leuven, Belgium. He was trained in Leuven and at the University of Minnesota, MN, USA, and obtained a doctoral degree in biomedical sciences. He is Clinical Head and directs the myeloma and myelodysplasia clinic of the Department of Hematology at University Hospital Leuven. Delforge is a member of the Executive Committee of the Stem Cell Institute Leuven and holds a hematology chair of the central fractionation unit of the Belgian Red Cross. He is an active member of the Belgian Myeloma Working Party, Intergroupe Francophone du Myélome (IFM), Dutch-Belgian Cooperative Trail Group for Hematological Oncology (HOVON) and International Myeloma Working Party (IMWG). His topics of interest include the side effects and management of new drugs in myeloma, translational research in myeloma and myelodysplastic syndromes.

What were the most important influencing factors that led to your interest in myeloma \& myelodysplasia?

As a student, I was already attracted to hematology because I felt it was a fascinating domain. No doubt the teaching skills of one of my mentors made a significant contribution to this. Although I first believed that cardiology would be my final destination, I came back to my 'first love': blood and bone marrow. As a clinical fellow, I became interested in complex diseases, such as myelodysplastic sydromes (MDS) and myeloma, and also in how patients try to cope with such devastating diseases. When I was offered the opportunity to study for a $\mathrm{PhD}$ in hematology at my institution, the subject proposed to me was myelodysplasia, and I became highly involved in this topic. However, I have to admit that the better I came to know multiple myeloma, the more I became involved in the treatment of these patients. After more than 10 years, I still feel fortunate to be able to do this job, although I have to admit that having to deal with cancer patients suffering from a chronic disease nearly every day can sometimes put you under significant psychological stress. Therefore, you need to have a good counterbalance for your physical and mental health. For myself, my family takes on this role, as well as my bike and, every once in a while, a dive in the swimming pool to refresh my mind. 


\section{What do you feel to be the main challenges facing clinicians working in the field of hematologic oncology in Belgium?}

First of all, I feel we are still in a very privileged situation. Personally, I work in the largest academic center of our country with many clinical and scientific opportunities. Although the environment is highly competitive, we consider this to be a positive incentive for improving yourself and your work. A challenge that many of us face is the high cost associated with many new anticancer drugs and the question of whether it will remain possible for a society to continue to pay such costs. The population of elderly and frail patients is rapidly growing, confronting us with major challenges in terms of how to optimize treatment for this rapidly expanding patient cohort. Finally, we urgently need predictive biomarkers in order to optimize treatment and use the available resources in the most optimal way.

One of your interests is based around translational research in myeloma. How has this area of research progressed in the past $5-10$ years $\&$ what further work is required?

It is a very fascinating and stimulating landscape to work in. First of all, new drugs have improved the outcomes for patients in a significant way, and that is what this is all about. As a student, I remember the devastating complications of multiple myeloma and the short life expectancy of many of these patients. Currently, things are rapidly improving, and it is stimulating to be able to contribute to this improvement. This major progress is due to the use of high-dose chemotherapy and, more recently, to the implementation of the so-called 'novel agents': thalidomide, lenalidomide and bortezomib. Currently, a newer generation of these drugs, such as pomalidomide, carfilzomib, other cell-specific molecules and monoclonal antibodies, are entering into clinical trials. Consequently, the therapeutic landscape is becoming much more complicated. Since the majority of myeloma patients relapse, and some relapses can be very aggressive, we need to continue to try to optimize first-line treatment by using strategies such as consolidation, maintenance or continuous treatment. A better knowledge of individual risk factors for early relapse and how to deal with minimal residual disease are among the highest priorities for further advancing the outcomes of myeloma patients.

\section{You are currently a member of the Executive Committee of the Stem Cell Institute in Leuven (SCIL). What does this institute set out to do \& what is your specific role?}

The SCIL was founded approximately 10 years ago and is chaired by Catherine Verfaillie. She is a world-renowned stem cell researcher and I spent some time in her laboratory in Minnesota when doing my PhD. As with many others, we were happy that she decided to come to Leuven some years ago. In this research institute, researchers around the globe work on stem cells and their potential applications. Currently, we are conducting an in-depth study of MDS stem cells, and we are also starting to look at 'myeloma stem cells'.

\section{Can you briefly explain to our readers about your part in the Belgian Myeloma Working Party?}

Since we are a small and bilingual country, we collaborate on Phase III studies with larger groups, such as the Dutch HOVON and the French IFM. However, we also deal with countryspecific issues, such as preparing guidelines for the diagnosis and treatment of plasma cell disorders and reimbursement of antimyeloma drugs, and we set up local investigator-driven trials in the field of myeloma.

\section{What research are you currently working on?}

Since I am a full-time clinician, the time for research projects can sometimes be limited. However, together with our data managers, we are actively involved in many Phase II and III trials in myeloma and MDS. In addition, together with Catherine Verfaillie, I coordinate other more basic research projects. One is directed at the stimulation of hematopoietic progenitor cells in low-risk MDS, and another one is aimed at a better characterization of myeloma stem cells. I sometimes feel a bit frustrated that my time for basic research is limited, but on the other hand, it is one of the major reasons why I remain in an academic center. Discussing with younger fellows stimulates your critical thinking and is a way to share your own knowledge and experience. 
Finally, what do you think will be the hot topics in hematologic oncology research over the next few years?

We have entered an era of novel diagnostic genetic tools that will help us to define diseases more specifically in an individual patient. The next challenge will be to use this and other diagnostic information in order to optimize patient treatment. In addition to this, designing an optimal treatment path for patients at diagnosis and at relapse will be of the utmost importance in order to help us to optimize treatment and obtain best results within the framework of the economic realism.

\section{Disclaimer}

The opinions expressed in this interview are those of the interviewee and do not necessarily reflect the views of Future Medicine Ltd.

Financial \& competing interests disclosure $M$ Delforge has provided consultancy services for Celgene, Janssen, Novartis and Amgen. M Delforge has no other relevant affiliations or financial involvement with any organization or entity with a financial interest in or financial conflict with the subject matter or materials discussed in the manuscript apart from those disclosed.

No writing assistance was utilized in the production of this manuscript. 